\section{Presence of enteric bacterial pathogens in meat samples of wild boar hunted in Campania region, southern Italy}

\author{
Maria Francesca Peruzy, ${ }^{1}$ \\ Daniela Cristiano, ${ }^{2}$ Elisabetta Delibato, ${ }^{3}$ \\ Nicola D'Alessio, ${ }^{4}$ Yolande T.R. \\ Proroga, ${ }^{2}$ Rosaria Luana Capozza, ${ }^{2}$ \\ Antonio Rippa, ${ }^{1}$ Nicoletta Murru ${ }^{1,5}$ \\ ${ }^{1}$ Department of Veterinary Medicine and \\ Animal Production, University of Naples \\ "Federico II"; 'Department of Food \\ Microbiology, Istituto Zooprofilattico \\ Sperimentale del Mezzogiorno, Portici, \\ NA; ${ }^{3}$ Department of Food Safety, \\ Nutrition and Veterinary Public Health, \\ Istituto Superiore di Sanita, Rome; \\ ${ }^{4}$ Department of Animal Health, Istituto \\ Zooprofilattico Sperimentale del \\ Mezzogiorno, Portici, NA; ${ }^{5}$ Task Force \\ on Microbiome Studies, University of \\ Naples Federico II, Naples, Italy
}

\begin{abstract}
Wild boars can be infected with several foodborne pathogens which may be transmitted to humans through the consumption of their meat, but currently, data of their prevalence are still limited. The present study aimed to evaluate the presence of enteric pathogens in wild boar meat samples killed in the Campania region. Twentyeight wild boar meat samples were analyzed for the detection of Salmonella spp, Y. enterocolitica, Campylobacter spp., and ShigaToxigenic E. coli.
\end{abstract}

Salmonella spp. was detected and isolated in ten samples and after serotyping $S$. Veneziana, $S$. Kasenyi, $S$. Coeln, $S$. Manhattan, $S$. Thompson, and $S$. Stanleyville were identified. Twenty-one meat samples were found to be contaminated with $Y$. enterocolitica; in 6 samples the $y s t \mathrm{~A}$ and $y s t \mathrm{~B}$ genes were detected simultaneously, while in 15 only the $y s t \mathrm{~B}$ gene, which characterizes the bacteria belonging to the biotype 1A, was present. Shiga-Toxin producing E. coli was detected in 12 while Campylobacter spp was never detected.

In conclusion, due to the high occurrence of pathogenic bacteria detected, the present research shows that wild boars are important reservoirs for foodborne zoonoses which may be transmitted to livestock and humans. This confirms the importance of controls throughout the wild boar supply chain. In the Campania region, checks are guaranteed by the Veterinarians who work within the "management and control plan for wild boar in the Campania region" which has the twofold objective of containing the increasingly invasive presence of this animal and guaranteeing greater safety, traceability, and transparency in the consumption of meat.

\section{Introduction}

Wild boars (Sus scrofa) are the most widely distributed large mammals in the world (Massei et al., 2015) and they are present in all continents, except for Antarctica (Sales et al., 2017). Wild boars are characterized by the highest reproductive rate among the ungulates and therefore in the latest years, the population is dramatically increased (Fredriksson-Ahomaa, 2019). Moreover, in recent years, they are introducing into a wide variety of habitats including urban and peri-urban areas (Bertelloni et al., 2020). Economic interest for these animals is related to the damage of crops and husbandry and the possibility of transmitting the disease to livestock and humans (Massei et al., 2015). The likely exchange of disease between wild boars, domestic animals, and humans raised increased interest also among researchers (Bonardi et al., 2019). In contrast to domesticated animals, wild boars roam free and their diet is uncontrolled, feeding of whatever is available, including live and dead animals (Fredriksson-Ahomaa, 2019). Therefore, the natural microbial population on the skin and in the digestive tract can significantly differ between the animals. Moreover, wild boars can be infected with several foodborne pathogens which may be transmitted to humans through the consumption of their meat. In the past, the wild boar meat was eaten only by hunters and their families but nowadays it is considered a healthy and delicious food and therefore it has drawn the attention of a wider range of consumers. Unfortunately, data on the consumption of wild boar meat at a European level are still limited. The meat of wild boars is mainly consumed cooked but though some wild boar meat products are not heat-treated but only dry-cured, cold smoked, and dried (Mirceta et al., 2017).

In the latest years, the four most reported zoonotic agents during gastrointestinal infection in humans were Campylobacter $(C$.$) , Salmonella (S$.$) , Shiga toxin-produc-$ ing E. coli (STEC), and Yersinia (Y.) (EFSA, 2021).

In 2019, 220,682 and 87,923 confirmed cases of campylobacteriosis and salmonellosis in humans were reported, respectively (EFSA, 2021). The main environmental
Correspondence: Daniela Cristiano, Department of Food Microbiology, Istituto Zooprofilattico Sperimentale del Mezzogiorno, Via Salute, 2, 8055, Portici, NA, Italy. Phone: 0817865229

E-mail: daniena.cristiano@izsmportici.it

Key words: Wild boar meat, Salmonella spp, Y. enterocolitica, Campylobacter spp., ShigaToxigenic E. coli.

Contributions: The authors contributed equally.

Conflict of interests: The authors declare no potential conflict of interests.

Funding: The study was supported by a grant from the Regione Campania UOD Prevenzione e Sanità Pubblica Veterinaria, Wild Boar Emergency Plan in Campania 2016-2019".

Availability of data and materials: All data and materials are available within the text.

Received for publication: 12 July 2021.

Accepted for publication: 19 November 2021.

This work is licensed under a Creative Commons Attribution-NonCommercial 4.0 International License (CC BY-NC 4.0).

CCopyright: the Author(s), 2022

Licensee PAGEPress, Italy

Italian Journal of Food Safety 2022; 11:9967

doi:10.4081/ijfs.2022.9967

niche for Campylobacter is represented by the intestinal tract of all avian species but Campylobacter species colonize also different apparatuses of domestic (cattle and pigs) or wild animals (birds such as ducks and gulls) and can be transmitted to humans through the consumption of this raw or undercooked meat (Facciolà et al., 2017). Concerning salmonellosis, in 2019, pig meat and products thereof were one of the most implicated food vehicles in strong-evidence food-borne outbreaks (EFSA, 2021).

Escherichia coli is a commensal bacterium living in the intestines of animals and humans but some pathotypes can be responsible for gastrointestinal infections: i) enteropathogenic E. coli (EPEC), ii) STEC, or verocytotoxin-producing $E$. coli (VTEC), iii) enterohemorrhagic E. coli (EHEC), iv) enteroinvasive E. coli (EIEC), v) enteroaggregative E. coli (EAEC or EAggEC), vi) enterotoxigenic E. coli (ETEC), vii) diffusely adherent $E$. coli (DAEC), and viii) adherent invasive E. coli (AIEC) (Bertelloni et al., 2020).

Compared to other foodborne bacteria very little data on the incidence of Y. enterocolitica in foods and animals are available 
from EU states probably because according to the Zoonoses Directive 2003/99/EC, reports of Yersinia occurrence or prevalence are not mandatory and even because current methods for the pathogen's isolation and detection proved to be undermined by several limitations (Cristiano et al, 2021; Peruzy et al., 2020). Strains of $Y$. enterocolitica can be classified into six biotypes 1A, $1 \mathrm{~B}, 2,3,4,5$ and at least 57 different serotypes. The biotype 1A has been considered as not pathogenic, though in the latest years has been associated with yersiniosis cases in humans (Strydom et al., 2019).

These enteric pathogens have been detected also in wild boar meat samples, but data are still limited. Therefore, the purpose of this work was to evaluate the prevalence of the most reported zoonotic agents, i.e. Campylobacter, Salmonella, Yersinia ente- rocolitica, and STEC in wild boar populations living in the Campania region.

\section{Materials and methods}

\section{Sampling}

From October 2019 to January 2020, meat samples of 28 wild boars (W1 to W28), 14 males (average weight: 53.57 $\mathrm{Kg}$ ), and 14 females (average weight: 47.07 $\mathrm{Kg}$ ), aged between 4 months and 7 years, were collected in Campania region, southern Italy (Table 1). The wild boars were hunted by official hunters by the "driving" technique. The animals were immediately bled in the field and brought to hunters' private houses where the evisceration and skinning were performed. Subsequently, approx. $100 \mathrm{~cm}^{2}$ meat was aseptically cut out the forearm area (at least $100 \mathrm{~g}$ each) and individually placed in sterile stomacher blender bags. All samples were transported at $4{ }^{\circ} \mathrm{C}$ to the laboratory and processed within one hour after sampling.

\section{Detection of pathogenic bacteria}

For the detection of relevant foodborne pathogens, 25 grams portions of each meat sample were homogenized separately i) in $225 \mathrm{ml}(1: 10(\mathrm{~W} / \mathrm{W}))$ buffer peptone water (BPW, CM0509, Oxoid) and incubated at $37^{\circ} \mathrm{C}$ for $24-\mathrm{h}$ for the detection of Salmonella (S.) and STEC, ii) in $225 \mathrm{ml}$ Campylobacter Bolton Enrichment Broth Base (Bolton Broth, 401286B2, Biolife), supplemented with Bolton Broth Selective Supplement (4240025, Biolife) and Lysed horse blood (90HLX100, Biolife) and incu-

Table 1. Gender, age (years $(\mathrm{Y}) /$ months $(\mathrm{M})$ ) and weight $(\mathrm{kg})$ of the shot animals, presence of foodborne bacteria genes detected using Real-Time PCR.

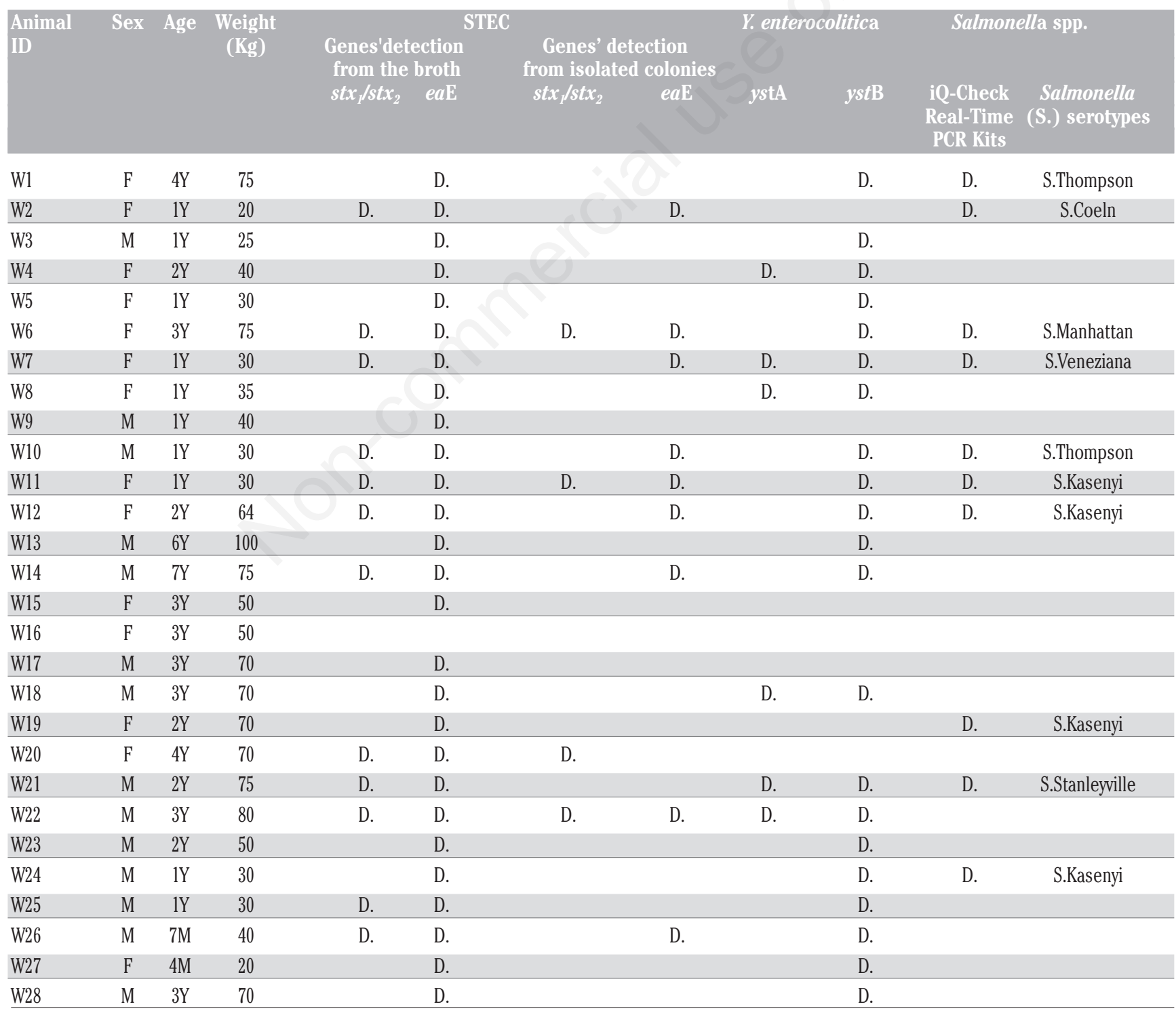

D: Detected. 
bated at $41.5^{\circ} \mathrm{C}$ in the microaerophilic atmosphere for 24-h for the detection of Campylobacter $(C$.), and iii) in $225 \mathrm{ml}$ Peptone Sorbitol Bile Broth (PSB, 17192, Sigma-Aldrich) and incubated at $25^{\circ} \mathrm{C}$ for 24-h for the detection of Yersinia ( $Y$.) enterocolitica. From each enrichment broth, the "iQ-Check Real-Time PCR Kits" were used for the detection of Salmonella (BR3578123, Bio-Rad, Hercules, CA, USA), STEC (BR3578139, Bio-Rad, Hercules, CA, USA), and Campylobacter (BR3578135, Bio-Rad, Hercules, CA, USA), following manufacturer's recommendations. Concerning STEC, the "iQCheck Real-Time PCR Kits", allowed the individual identification of the virulence genes $s t x_{1}$ and stx $_{2}$ (Shiga toxin 1/2) and eae (intimin). For the detection of $Y$. enterocolitica, DNA was extracted from each enrichment broth using the Chelex100 -resin method (1422822, Bio-Rad, Hercules, CA, USA) whereby two $\mathrm{ml}$ of each incubated homogenate was transferred into a two $\mathrm{ml}$ centrifuge tube and centrifuged for $10 \mathrm{~min}$ at $10,000 \times g$ at $4^{\circ} \mathrm{C}$. The supernatant was discarded, the pellet re-suspended in $300 \mu \mathrm{l}$ of $6 \%$ Chelex 100 by vortexing, and incubated for $20 \mathrm{~min}$ at $56^{\circ} \mathrm{C}$ and again for $8 \mathrm{~min}$ at $100^{\circ} \mathrm{C}$. The suspension was immediately chilled on ice for 1 min and centrifuged for $5 \mathrm{~min}$ at $10,000 \times \mathrm{g}$ at $4{ }^{\circ} \mathrm{C}$. To evaluate the presence of $Y$. enterocolitica 4/O:3 and biotype 1A, a SYBR green PCR-assay was conducted, with the gene ystA as target for the pathogenic biotype (Peruzy et al., 2017). Therefore, $3 \mu$ of DNA extract was added to $22 \mu \mathrm{l}$ of PCR mix. The mastermix contained $12.5 \mu \mathrm{l}$ of Qiagen QuantiTect SYBR Green PCR Kit (1x), $100 \mathrm{nM}$ of both primers ystA-F (5'ATCGACACCAATAACCGCTGAG-3') and $y s t \mathrm{~A}-\mathrm{R} \quad\left(5^{\prime}\right.$-CCAATCACTACTGACTTCGGCT-3'). To evaluate the presence of the biotype $1 \mathrm{~A}$, the presence of the target gene ystB gene was examined (Peruzy et al., 2017). Three $\mu$ of DNA extract was added to $22 \mu \mathrm{l}$ of PCR mastermix containing $12.5 \mu \mathrm{l}$ of Qiagen QuantiTect SYBR Green PCR Kit (1x), $150 \mathrm{nM}$ of both primers ystB-F (5'-GTACATTAGGCCAAGAGACG-3') and ystBR (5'-GCAACATACCTCACAACACC-3'). The fluorescence of SYBR Green and the melting curve was generated using the CFX96 system (Bio-Rad). A specific melting temperature $\left(\mathrm{T}_{\mathrm{m}}\right)$ of $78.5 \pm 1^{\circ} \mathrm{C}$ indicated a positive result. While awaiting the RealTime PCR (RT-PCR) results, the enrichment broths were stored at $4{ }^{\circ} \mathrm{C}$. Real-Time PCR positive results for Salmonella spp., STEC, Campylobacter, or Y. enterocolitica were confirmed using the corresponding normalized microbiological isolation meth- ods ISO $\quad 6579-1: 2017, \quad 13136-1: 2012$, 10272-1:2017 and 10273:2017. Concerning STEC, colony confirmation was performed by mean the "iQ-Check Real-Time PCR Kits".

\section{Statistical analysis}

To compare the bacterial counts, a oneway analysis of variance (ANOVA) was calculated using PAST software package (https://folk.uio.no/ohammer/past/).

\section{Results and discussion}

Wild boars are an important reservoir of zoonoses whose frequency may vary across populations living in different countries and even in different regions within the same country (Gill, 2007). Some of these can cause foodborne illness in humans, who may be infected by consuming contaminated wild boar meat. Among them, a good deal has an enteric origin, and the presence of them on the carcass surface is mainly the result of an improper evisceration (Sánchez-Rodríguez et al., 2018). In the present study, a total of 28 samples were analyzed for enteric pathogens' detection and except for Campylobacter all the other genes investigated were detected. The overall percentage of wild boars positive per at least one of the enteric pathogen genes tested was $96.43 \%$ (Table 1). No significant correlation was observed between genes detection and the gender, age, and weight of the animals.

Salmonella spp. was detected and isolated in 10 out of 28 enrichment broths analyzed $(35.71 \%)$ and after serotyping six serovars were identified $(S$. Coeln, $S$. Kasenyi, $S$. Manhattan, $S$. Stanleyville, $S$. Thompson, and $S$. Veneziana). The occurrence of Salmonella is comparable to that we observed previously in wild boars hunted in the Campania region in 2017 (31.82\%, Peruzy et al., 2019) but it was higher than those observed by Atanassova et al., (2008) in Germany, Peter Paulsen \& Winkelmayer, (2004) in Austria, Mirceta et al., (2017) in Serbia, and Wacheck et al., (2010) in Switzerland. Considering the serovars, $S$. Kasenyi was the most frequently isolated (W11, W12, W19, and W24). S. Kanseny is frequently isolated in the wild boar population living in the Campania region (La Tela et al., 2021; Peruzy et al., 2019) but, to our knowledge, it has not been reported in any other wild boar living in other regions or other countries. Differently, $S$. Thompson detected in the present study in two animals (W1 and W10) is widespread in wild boar population and several other animal species and it has been associated with a severe human outbreak in the Netherlands in 2012 (Stella et al., 2018). S. Veneziana, S. Stanleyville, $S$. Manhattan, and $S$. Coeln detected in the present work have been previously isolated in wild boars (Bonardi et al., 2019; Razzuoli et al., 2021) and S. Coeln belong to the 20 most frequent serovars isolated in human cases in Europe (EFSA, 2021).

In the present study, $Y$. enterocolitica and STEC were detected in a high number of enrichment broths. Concerning $Y$. enterocolitica, six enrichment broths $(21.43 \%)$ carried both $y s t \mathrm{~A}$ and $y s t \mathrm{~B}$ genes, whilst in fifteen $(53.57 \%)$ only the gene $y s t \mathrm{~B}$, used as a target for Biotype 1A (Peruzy et al., 2017), was detected. However, the pathogen was only isolated from one sample (W18). Pigs are considered the major reservoir where the bacterium has been commonly isolated from the tonsils and gastrointestinal tract and the contamination of the meat result from improper slaughter and evisceration techniques (Fredrikssonahomaa et al., 2006). Results of the present work confirm that wild boars could be considered an underestimated reservoir of $Y$. enterocolitica, as well (Morka et al., 2018).

Concerning STEC, except for the animal W16 the gene eae was detected in all enrichment broths analysed. Genes stx $x_{1}$ and $s t x_{2}$ were always detected together. Twelve enrichment broths $(42.86 \%)$ were positive for both $s t x_{1} / s t x_{2}$ and eae genes, whilst in fifteen enrichment broths $(53.57 \%)$ only the gene eae was detected. Only in four and nine strains the genes $s t x_{1} / s t x_{2}$ and eae, respectively, were also detected from the colony's growth on the agar plates.

The gene eae responsible for the typical attaching and effacing lesions was used as a target for the detection of Enteropathogenic E. coli (EPEC), which are defined as intimin (eae)-containing diarrheagenic $E$. coli that do not possess the stx genes (Alonso et al., 2017). Wild boars acting as a carrier of EPEC have been previously demonstrated by SzczerbaTurek et al., (2019) who detected them in $30.9 \%$ of the animals and other Spanish and Italian studies but a lower occurrence was reported (Spain $=3.3 \%$, Alonso et al., 2017; Italy $=3.4 \%$, Bertelloni et al., 2020).

Moreover, based on results, wild boars act also as carriers of Enterohaemorrhagic E. coli (EHEC). In particular, the co-carriage of both stx and eae genes indicates the presence of EHEC which constitutes a subset of serotypes of STEC, (Kobayashi et al., 2003). EHEC responsible for both Shigatoxins production and attaching and effacing lesions is associated with severe forms of human disease (Soare et al., 2021). To our knowledge, lim- 
ited data are available on the occurrence of EHEC in wild boars, however, the results of the present work contrast with those of Bertelloni et al. (2020) which reported a lower occurrence of EHEC (6.3\%).

In the present work Campylobacter, the most reported gastrointestinal bacterial pathogen in humans in the European Union (EU) (EFSA, 2021), was never detected. A low occurrence was demonstrated also by Fredriksson-Ahomaa et al., (2020, 5\%), and Atanassova et al., (2008, 2.1\%), whilst a higher occurrence was observed by Stella et al., (2018, 16.7\%).

\section{Conclusions}

In conclusion, due to the high occurrence of pathogenic bacteria detected, the present research shows that wild boars are important reservoirs for foodborne zoonoses. Therefore, based on results consumption of undercooked wild boar meat could pose a public health risk. Moreover, the spread of pathogenic bacteria in the natural environment constitutes a potential hazard also for domestic animals. In the Campania region, checks are guaranteed by the Veterinarians who work within the "management and control plan for wild boar in the Campania region" which has the twofold objective of containing the increasingly invasive presence of this animal and guaranteeing greater safety, traceability and transparency in the consumption of meat.

\section{References}

Alonso CA, Mora A, Díaz D, Blanco M, González-Barrio D, Ruiz-Fons F, Simón C, Blanco J, Torres C, 2017. Occurrence and characterization of stx and/or eae-positive Escherichia coli isolated from wildlife, including a typical EPEC strain from a wild boar. Vet Microbiol 207:69-73.

Atanassova V, Apelt J, Reich F, Klein G, 2008. Microbiological quality of freshly shot game in Germany. Meat Sci 78:414-9.

Bancerz-kisiel A, Szweda W, 2015. Yersiniosis - a zoonotic foodborne disease of relevance to public health. Ann Agr Env Med 22;397-402.

Bertelloni F, Cili, G, Bogi S, Ebani VV, Turini L, Nuvoloni R, Cerri D, Fratini F, Turchi B, 2020. Pathotypes and antimicrobial susceptibility of Escherichia coli isolated from wild boar (Sus scrofa) in Tuscany. Animals 10:1-12.

Bonardi S, Bolzoni L, Zanoni RG, Morganti M, Corradi M, Gilioli S, Pongolini S, 2019. Limited Exchange of Salmonella
Among Domestic Pigs and Wild Boars in Italy. Ecohealth 16:420-8.

Cristiano D, Peruzy MF, Aponte M, Mancusi A, Proroga YTR, Capuano F, Murru N, 2021 Comparison of droplet digital PCR vs real-time PCR for Yersinia enterocolitica detection in vegetables. Int $\mathrm{J}$ Food Microbiol 109321.

EFSA, ECDC (European Food Safety Authority and European Centre for Disease Prevention and Control), 2021. The European Union One Health 2019 Zoonoses Report. EFSA J 19:6406,

Facciolà A, Riso R, Avventuroso E, Visalli G, Delia SA, Laganà P, 2017. Campylobacter: from microbiology to prevention. J Prev Med Hyg 79-92.

Fredriksson-Ahomaa, M, 2019. Wild Boar: A Reservoir of Foodborne Zoonoses. Foodborne Pathog Dis 16:153-65.

Fredriksson-Ahomaa M, London L, Skrzypczak T, Kantala T, Laamanen I, Biström M, Maunula L, Gadd T, 2020. Foodborne Zoonoses Common in Hunted Wild Boars. Ecohealth

Fredriksson-ahomaa M, Stolle A, Korkeala H, 2006. Molecular epidemiology of Yersinia enterocolitica infections. Fems Immunol Med Mic.

Gill CO, 2007. Microbiological conditions of meats from large game animals and birds. Meat Sci 77:149-60.

Kobayashi H, Miura A, Hayashi H, Ogawa T, Endo T, 2003. Prevalence and characteristics of eae-positive Escherichia coli from healthy cattle in Japan. Appl Environ Microb 69:5690-2.

La Tela I, Peruzy MF, D'Alessio N, Di Nocera F, Casalinuovo F, Carullo MR, Cardinale D, Cristiano, D, Capuano F, 2021. Serotyping and evaluation of antimicrobial resistance of salmonella strains detected in wildlife and natural environments in southern Italy. Antibiotics 10:1-13.

Massei G, Kindberg J, Licoppe A, Gačić D, Šprem N, Kamler J, Baubet E, Hohmann U, Monaco A, Ozoliņš J, Cellina S, Podgórski T, Fonseca C, Markov N, Pokorny B, Rosell C, Náhlik A, 2015. Wild boar populations up, numbers of hunters down? A review of trends and implications for Europe. Pest Manag Sci 71:492-500.

Mirceta J, Petrovic J, Malesevic M, Blagojevic B, Antic D, 2017. Assessment of microbial carcass contamination of hunted wild boars. Eur J Wildl Res 63.

Morka K, Bania J, Korzeniowska-kowal A, Korzekwa K, Guz-regner K, Bugla-p G, 2018. Identification of Yersinia enterocolitica isolates from humans, pigs and wild boars by MALDI TOF MS. BMC Microbiol 1-10.

Paulsen P, Winkelmayer R, 2004. Seasonal variation in the microbial contamination of game carcasses in an Austrian hunting area. Eur J Wildl Res 50:157-9.

Peruzy MF, Aponte M, Proroga YTR., Capuano F, Cristiano D, Delibato E, Houf K, Murru N, 2020. Yersinia enterocolitica detection in pork products: Evaluation of isolation protocols. Food Microbiol 92:103593.

Peruzy MF, Murru N, Perugini AG, Capuano F, Delibato E, Mercogliano R, Korkeala H, Proroga YTR., 2017. Evaluation of virulence genes in Yersinia enterocolitica strains using SYBR Green real-time PCR. Food Microbiol 65:231-5.

Peruzy MF, Murru N, Yu Z, Kerkhof P, Neola B, Joossens M, Proroga YTR, Houf K, 2019. International Journal of Food Microbiology. Assessment of microbial communities on freshly killed wild boar meat by MALDI-TOF MS and 16S rRNA amplicon sequencing. Int J Food Microbiol 301:51-60.

Razzuoli E, Listorti V, Martini I, Migone L, Decastelli L, Mignone W, Berio E, Battistini R, Ercolini C, Serracca L, Andreoli T, Dellepiane M, Adriano D, Pitti M, Meloni D, Modesto P, 2021. Prevalence and antimicrobial resistances of salmonella spp. Isolated from wild boars in Liguria region, Italy. Pathogens 10:1-12.

Sales LP, Ribeiro BR, Hayward MW, Paglia A, Passamani M, Loyola R, 2017. Niche conservatism and the invasive potential of the wild boar. J Anim Ecol 86:1214-23.

Sánchez-Rodríguez JA, Navas L, Vinuesa FM, Castells C, Martínez MA, López A, Lindez B, Cabrera-Vique C, 2018. New insights on the risk factors associated with the presence of Salmonella on pig carcasses. Lessons from small slaughterhouses. Food Control 87:46-52.

Soare C, McNeilly TN, Seguino A, 2021. A review of potential risk factors linked to shiga toxin-producing Escherichia coli (STEC) in wild deer populations and the practices affecting the microbial contamination of wild deer carcasses with enteric bacteria. Food Control 127:108128.

Stella S, Tirloni E, Castelli E, Colombo F, Bernardi C, 2018. Microbiological evaluation of carcasses of wild boar hunted in a hill area of northern Italy. J Food Prot 81:1519-25.

Strydom H, Wang J, Paine S, Dyet K, Cullen K, Wright J, 2019. Evaluating sub-typing methods for pathogenic 
Yersinia enterocolitica to support outbreak investigations in New Zealand. Epidemiol Infect 147:1-7.

Szczerba-Turek A, Socha P, Bancerz-Kisiel A, Platt-Samoraj A, Lipczynska-Ilczuk K, Siemionek J, Kończyk K, Terech-
Majewska E, Szweda W, 2019. Pathogenic potential to humans of Shiga toxin-producing Escherichia coli isolated from wild boars in Poland. Int J Food Microbiol 300:8-13.

Wacheck S, Fredriksson-Ahomaa M, Konig
M, Stolle A, Stephan R, 2010. Wild Boars as an Importat Reservoir for Foodborn Pathogens. Foodborne Pathog Dis 7:307-12. 